\title{
Erratum to: Thermo-mechanical vibration of rotating axially functionally graded nonlocal Timoshenko beam
}

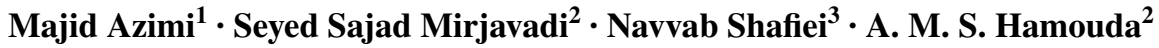

Published online: 30 January 2017

(C) Springer-Verlag Berlin Heidelberg 2017

\section{Erratum to: Appl. Phys. A (2017) 123:104}

DOI 10.1007/s00339-016-0712-5

The original version of this article unfortunately contained a mistake. The affiliation 3 was incorrect. The correct affiliation 3 is:

Department of Mechanical Engineering, Payame Noor University (PNU), P. O. Box 19395-3697, Tehran, Iran.

The online version of the original article can be found under doi:10.1007/s00339-016-0712-5.

Seyed Sajad Mirjavadi

s.mirjavadi@ut.ac.ir

1 School of Mechanical Engineering, College of Engineering, Sharif University of Technology, Tehran 11365-11155, Iran

2 Mechanical and Industrial Engineering Department, College of Engineering, Qatar University, 2713 Doha, Qatar

3 Department of Mechanical Engineering, Payame Noor University (PNU), P. O. Box 19395-3697, Tehran, Iran 